\title{
Effects on the Linac Beam from Random Noise in Quads
}

\author{
Milorad Popovic, Trevor Butler, Doug Moehs
}

May 18, 2005

\begin{abstract}
This report describes a PARMILA ${ }^{1}$ simulation of the Fermilab Drift Tube Linac (DTL). Effects on the $\mathrm{H}^{-}$beam associated with random noise on the DTL quadrupole currents are studied.
\end{abstract}

\section{Introduction}

The Fermilab DTL was built in the late 1960's and the original power supplies for the quadrupole magnets (quads) are still in use. With the exception of a few systems, most of the quadrupole power supplies are used to power two quads at a time along with a matching tap transformer. These power supplies contain capacitors with PCB's and regulation components that are becoming hard to maintain. As part of the Fermilab Proton Plan ${ }^{2}$, the decision was made to completely replace all of the power supplies with new power supplies similar to the ones used in the $400 \mathrm{MeV}$ Linac upgrade. As part of the specifications for the new supplies, it was assumed that regulation of the operating current to $\pm 0.5 \%$ was good enough to preserve the present beam properties. This study has been carried out in an effort to confirm this assumption.

\section{Method and Results}

The PARMILA code was used to simulate the effects of quad power supply noise on the $\mathrm{H}^{-}$beam in the Fermilab DTL. It is assumed that this noise comes from the power supplies. To establish a reference for comparison, the current of each quad in the DTL was read from the control system and this data was used to produce run 1 in PARMILA for each study. The PARMILA simulations start at the exit of the 90 degree bending magnet in the $750 \mathrm{keV}$ line, just up stream of tank \#1, and ends immediately after tank \#5. In this report two different noisy power supply situations were considered. Study 1 looks at the effect of a single noisy power supply and study 2 looks at the possibility that all the quad power supplies are noisy at the $\pm 0.5 \%$ level.

\section{$\underline{\text { Study } 1}$}

In study one it was assumed that only a single power supply has problems regulating at the $\pm 0.5 \%$ level. For this study, the quad power supply associated with drift tubes four and five in Tank \#1 was selected. At this location in the DTL transfer function is large and the quad current is high, these conditions imply that the beam should be sensitive to current fluctuations at this location. For this study $1 \times 10^{5}$ particles were simulated. 
Table 1: Run 1 data after tank \#5. The quadrupole currents were read from control system.

\begin{tabular}{|c|c|c|c|c|c|c|c|c|c|}
\hline Cell & $\begin{array}{l}\text { Number } \\
\text { Of } \\
\text { Good } \\
\text { Particles }\end{array}$ & Plane & \multicolumn{3}{|c|}{$\begin{array}{l}\text { Emittance } \\
\text { (cm-rad) or (Deg-Mev) }\end{array}$} & Alpha & $\begin{array}{l}\operatorname{Beta}(\mathrm{u}) \\
(\mathrm{cm} / \mathrm{mrad}) \\
\text { or } \\
(\mathrm{deg} / \mathrm{MeV})\end{array}$ & $\begin{array}{l}\text { Rms }(\mathrm{u}) \\
\mathrm{X} \text { or } \mathrm{Y} \\
(\mathrm{cm})\end{array}$ & $\begin{array}{l}\text { Max } \\
\text { X or } \\
Y \\
(\mathrm{~cm})\end{array}$ \\
\hline \multirow{3}{*}{24} & \multirow{3}{*}{74495} & $x-x^{\prime}$ & 1.67477 & 0.42834 & 0.07565 & -1.2965 & 0.600365 & 0.2963 & 1.3927 \\
\hline & & $y-y^{\prime}$ & 3.06 & 0.83928 & 0.13 & 1.2633 & & 0.3251 & 1.1263 \\
\hline & & Phi-w & 11.41648 & .84919 & 0.38730 & 0.7492 & 20.265144 & 2.8015 & 0.0000 \\
\hline
\end{tabular}

End Cell Calculated Phase: -31.8128

End Cell Design Phase: -32.0

End Cell Calculated Energy (Mev): 116.0020

End Cell Design Energy (MeV): 117.0443

Table 2: Run 2 data after Tank \# 5. The quad cu rrent associated with drift tubes four and five in Tank \#1 was increased by $0.5 \%$ relative to run 1 .

\begin{tabular}{|c|c|c|c|c|c|c|c|c|c|}
\hline Cell & $\begin{array}{l}\text { Number } \\
\text { Of } \\
\text { Good } \\
\text { Particles }\end{array}$ & Plane & $\begin{array}{l}\text { Emittance } \\
\text { (cm-rad) }\end{array}$ & Deg-M & rms n. & Alpha & $\begin{array}{l}\operatorname{Beta}(\mathrm{u}) \\
(\mathrm{cm} / \mathrm{mrad}) \\
\text { or } \\
(\mathrm{deg} / \mathrm{MeV})\end{array}$ & $\begin{array}{l}\text { Rms }(\mathrm{u}) \\
\mathrm{X} \text { or Y } \\
(\mathrm{cm})\end{array}$ & $\begin{array}{l}\text { Max } \\
\text { X or } \\
Y \\
(\mathrm{~cm}) \\
\end{array}$ \\
\hline \multirow{3}{*}{24} & \multirow{3}{*}{74619} & $x-x^{\prime}$ & 1.66566 & 0.43075 & 0.07581 & -1.2965 & 0.600365 & 0.2974 & 1.3927 \\
\hline & & $y-y^{\prime}$ & 2.908 & 0.84041 & 0.138 & 1.26338 & 0.3935 & 0.3251 & 1.1263 \\
\hline & & Phi-w & 18.48678 & 1.87870 & 0.38945 & 0.74924 & 20.262478 & 2.8091 & 0.0000 \\
\hline
\end{tabular}

End Cell Calculated Phase: -31.8105

End Cell Calculated Energy (Mev): 116.0020

End Cell Design Phase: -32.0

End Cell Design Energy (MeV): 117.0443

From table 1 the transmission through Tank 5 is $74.4 \%$. A comparison of the data in tables 1 and 2 show that there is a $0.2 \%$ change in the $\mathrm{H}^{-}$transmission when a single quad current is increased by $0.5 \%$. A similar change in transmission results when the current is decreased by $0.5 \%$.

\section{Study 2:}

In study two it was assumed that all the DTL quadrupole power supplies have a problem regulating at the $\pm 0.5 \%$ level. 12 independent runs of $1 \times 10^{4}$ particles were completed. In run 1 (the reference) the transmission was $74 \%$, that is 7415 particles were counted at the end of Tank \#5. For runs 1-11 the percent change in transmission and RMS emittance is shown in figure 1-4 with run 1 being used as the reference. For runs 2-11 the quad currents were changed in the range of $\pm 0.5 \%$ from the nominal values of run 1 which were read from the control system. 

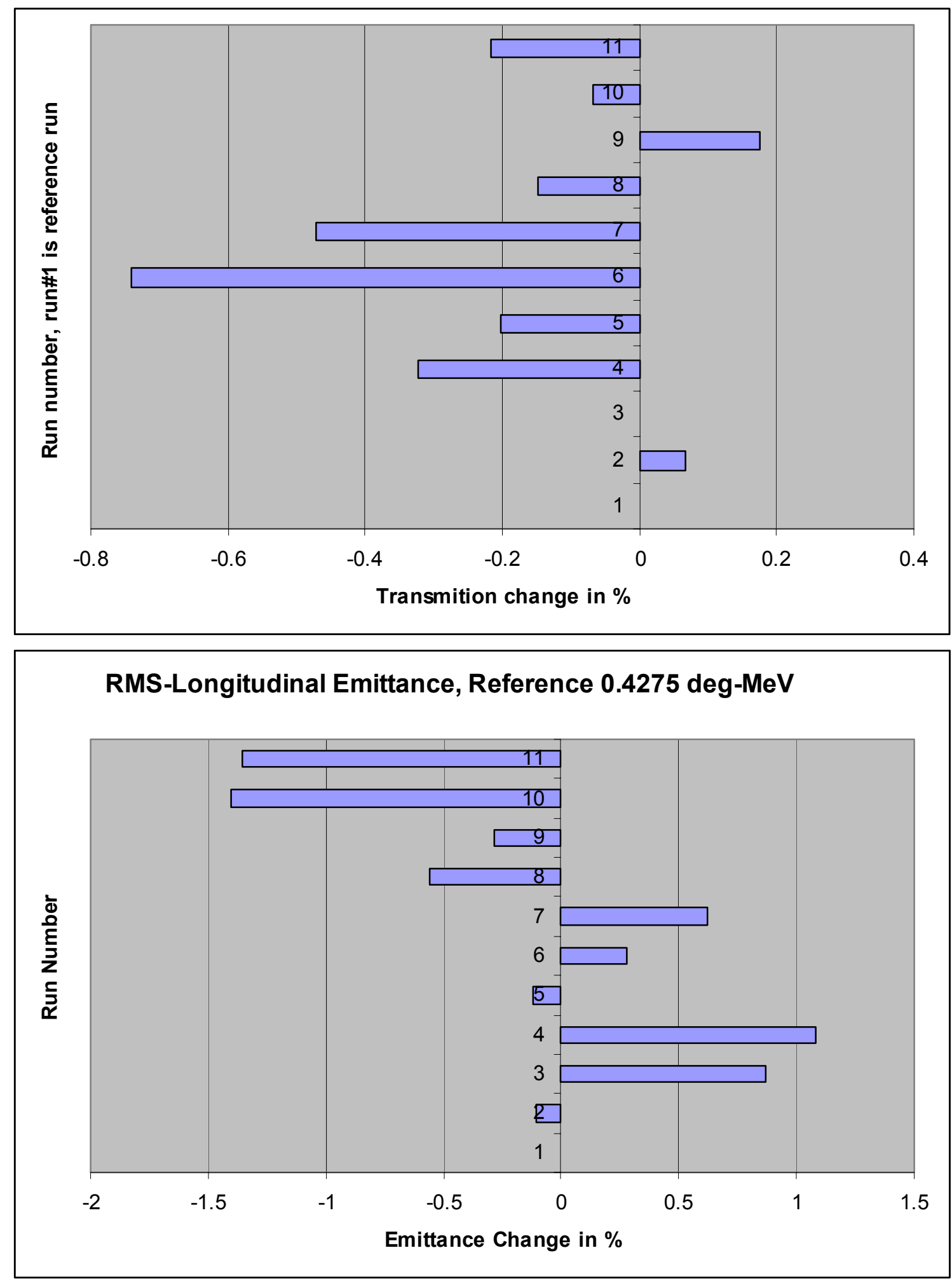

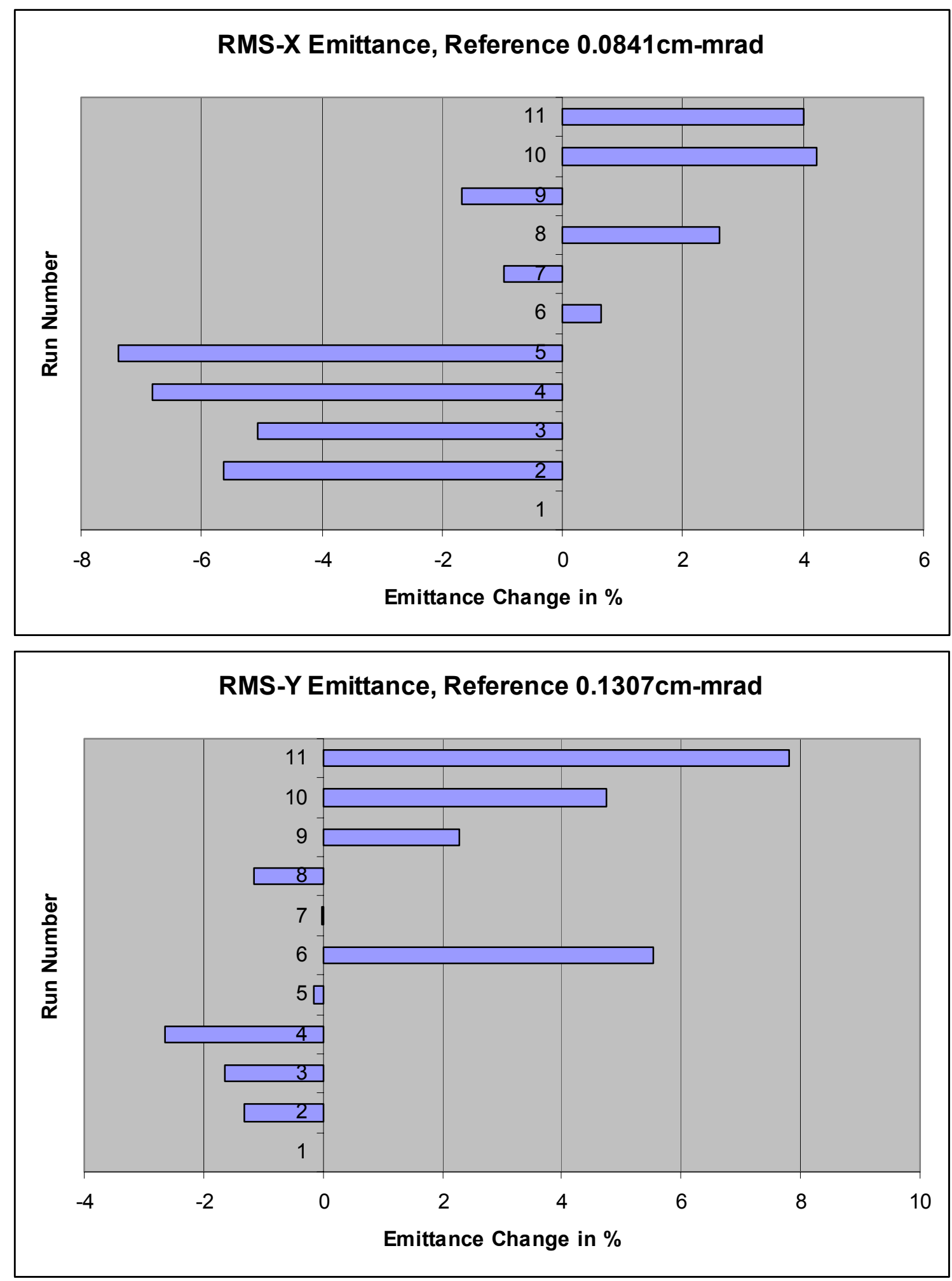

Figure 1-4: Percent change in transmission and RMS emittance using run 1 as the reference. 


\section{Conclusion:}

Based on these studies a $\pm 0.5 \%$ change in the current of any one quadrupole power supply is not large enough to significantly affect the beam. Further more, the data of study 2 shows that a random change of $\pm 0.5 \%$ applied to all the DTL quadrupole currents does not significantly affect the transmission through the DTL. The changes in the longitudinal and transverse RMS emittances calculated in these studies are much smaller that what can be measured.

\footnotetext{
1 “Parmila," Harunori Takeda, Documentation by James H. Billen, Los Alamos National Laboratory, LAUR-98-4478, Revised April 29, 2005

2 “Proton Plan", Accelerator Division, Fermilab, Beams Doc. 1441, Revised Nov. 9, 2004. Available: http://www.fnal.gov/directorate/program_planning/Nov2004PACPublic/Draft_Proton_Plan_v2.pdf
} 